LETTER TO JMG

\title{
Refining the phenotype of common mutations in Rett syndrome
}

\author{
L Colvin, H Leonard, N de Klerk, M Davis, L Weaving, S Williamson, J Christodoulou
}

J Med Genet 2004;41:25-30

$\mathrm{R}$ ett syndrome (RTT; MIM No 312750) is a neurodevelopmental disorder mainly affecting girls, with an incidence of 1:10 000 female births. ${ }^{1}$ The clinical features of the syndrome were first described in a series of publications ${ }^{2-5}$ during the decade after it was first reported in English language journals. ${ }^{6}$ At that time, in the absence of a biological marker, criteria to assist with the diagnosis were developed by an international working group. ${ }^{7}$ These criteria relate to the typical characteristics which are: normal prenatal and perinatal period and apparently normal development for the first six months of life; deceleration in head growth; loss of hand and communication skills between six and 30 months; apparent severe psychomotor retardation; acquisition of stereotypical hand movements; and evidence of gait or truncal apraxia between one and four years. These necessary criteria were supplemented by a set of supportive but not mandatory criteria, which help to delineate the phenotype further. These include breathing dysfunction, EEG abnormalities, seizures, spasticity, peripheral vasomotor disturbance, scoliosis, growth retardation, and hypotrophic small feet.

In 1999 the association between Rett syndrome and mutations in the methyl-CpG binding protein 2 (MECP2; MIM No 300005) located on Xq28 was first identified. ${ }^{8}$ In the last decade there had already been much commentary about the expanding clinical spectrum of Rett syndrome and the occurrence of atypical forms. ${ }^{9}$ This culminated in 2001 in a meeting to revise the existing diagnostic criteria. ${ }^{10}$ It is now clear that, although this condition must be considered a severe neurodevelopmental disorder, there is still considerable variation in both functioning and associated morbidity, even in those cases with confirmed MECP2 mutations. We have been able to demonstrate this variability ${ }^{11}$ using a tool to measure functional ability ${ }^{12}$ and three clinical scales. The first was developed by Kerr et $a l^{13}$ the second was modified by Percy and Schanen (personal communication, 11 September 2001) from Amir et al, ${ }^{14}$ and the third was modified by Pineda from Monros et al. ${ }^{15}$

Since 1999 much research has been undertaken to try to identify the genetic determinants of this phenotypic variability. ${ }^{16-21}$ Genetic factors considered include the type and domain of mutation and the modulating role of $X$ inactivation. $^{22} \mathrm{X}$ inactivation is a gene dosage compensation mechanism in mammals equalising $X$ linked gene products between $\mathrm{XX}$ females and $\mathrm{XY}$ males. ${ }^{23}$ The preferential silencing of one $X$ chromosome may lead to skewed $X$ inactivation, which can be either favourable or detrimental. Thus the proportion of cells that have inactivated the normal $\mathrm{X}$ chromosome may influence the difference in severity between individuals with the same mutation.

Until now much of the published work relating to genotype-phenotype correlation has been limited by lack of uniformity in clinical scales and categorisation of mutation type across studies, as well as by small sample sizes. In the years since the identification of the disease associated gene, research findings in this regard remain somewhat contradictory. Thus the child neurology community does not

\section{Key points}

- Although Rett syndrome is recognised as a severe neurological condition associated with mutations in the MECP2 gene, there is much variation in both functioning and associated morbidity. The Australian Rett syndrome database is a valuable resource for comparing genotypic and phenotypic characteristics.

- Using this database it was found that mutations in the nuclear localisation signal (NLS) region within the TRD location were significantly more severe. The only difference, however, between TRD and MBD mutations was in voluntary hand use, where the MBD group retained more use.

- A less severe phenotype was found in the region after the TRD-NLS including the C-terminal region. R270X, located in the NLS of the TRD, was the most severe of the common mutations, in direct contrast to R294X, which was also found in the TRD domain but after the NLS and had a milder phenotype.

- In this report, a population based registry was used to quantify the phenotypes, particularly those associated with some of the more common MECP2 mutations.

yet have a clear message regarding what phenotype to expect in children with specific groups of MECP2 mutations. In Australia we have had the advantage of being able to study phenotypic characteristics including functional ability, developmental history, and current morbidity status on a population basis. ${ }^{11}$ The Australian Rett syndrome database (ARSD), which was set up in 1993, is a unique national registry of cases born since 1976. It provides an infrastructure for epidemiological, clinical, and genetic research and the capacity for longitudinal follow up of a population based cohort. Inclusion of molecular data now enhances the registry $^{22}$ and allows clinical features to be compared according to genetic characteristics, including $\mathrm{X}$ inactivation status.

From a review of available published and unpublished cases in 2000, Dragich et al reported that eight recurrent missense and nonsense mutations (R106W, R133C, T158M, R168X, R255X, R270X, R294X, and R306C) accounted for up to two thirds of pathogenic mutations identified in Rett syndrome. ${ }^{24}$ In Australia we have found seven of these (all but Rl06W), each occurring in seven or more cases in our cohort (table 1). In conjunction with data from the United

Abbreviations: ARSD, Australian Rett syndrome database; DHPLC denaturing high performance liquid chromatography; $M B D$, methylCpG-binding domain; NLS, nuclear localisation signal; TRD, transcription repression domain; $\mathrm{XCl}, \mathrm{X}$ chromosome inactivation 
Kingdom and Japan, we have already shown that one of these-the R133C, a missense mutation in the methyl binding domain-has a significantly milder phenotype when compared with all other pathogenic mutations. ${ }^{21}$ However, up to now the phenotypic characteristics of the remaining common mutations have not been examined individually either by us or by others.

Our aims in this study were twofold: using better phenotype descriptors, we sought to extend previous research which has grouped mutations according to mutation type and domain location; and second, to investigate whether differences in severity of phenotype can be identified among the more common mutations.

\section{METHODS}

As in previous studies, ${ }^{11}{ }^{21}$ cases were sourced from the ARSD. By early 2003, 247 verified cases of Rett syndrome had been reported using our categorisation system, ${ }^{1}$ with 117 (47\%) categorised as classical and $130(53 \%)$ as atypical. Twelve cases had died since ascertainment. Families of a further 11 cases were not currently in contact with the registry, and 25 are newly ascertained cases since 2000 . Mutation testing has been undertaken on 196 of the 247 cases, with pathogenic mutations identified in 129 (66\%). Data used in this study relate to the cases whose parents or carers completed the Australian follow up study in $2000(\mathrm{n}=163)$, providing current functional and behavioural information. Of the 163 , 147 (90\%) have been screened for MECP2 mutations, and this study is restricted to those of the 147 in whom a mutation considered pathogenic had been identified $(\mathrm{n}=109$, with an age range of 2.0 to 24.6 years; mean (SD), 13.7 (6.1) years). $\mathrm{X}$ inactivation studies have now been completed on $94(86 \%)$ of these cases.

Cases were again scored using four composite scales (Kerr, ${ }^{13}$ Percy, ${ }^{14}$ Pineda, ${ }^{15}$ and WeeFIM ${ }^{12}$ ), as well as according to the individual components of these scales. ${ }^{11}$ Mutation characteristics were categorised and grouped for analysis in a variety of ways:

- Type of sequence change ${ }^{25}$ - "mutation type": missense $(40.4 \%)$ and truncating (nonsense $(39.5 \%)$ and frameshift $(18.4 \%))$ were considered individually and compared with the rest of the cohort with pathogenic mutations.

- Domain location-cases were ordered according to nucleotide sequence into their domain locations. Five main locations were identified in our cohort: methyl-CpGbinding domain (MBD); interdomain; transcription repression domain-nuclear localisation signal (TRDNLS); TRD-after NLS; and C-terminal. These were considered individually and compared with the rest of the cohort with pathogenic mutations (table l, fig l).

- Seven common mutations (referred to by the amino acid change) were considered individually and compared with the rest of the cohort with pathogenic mutations (table 2, fig 2).

Initially, phenotypic characteristics were compared between mutation types, domain locations, specific mutations, and the rest of the cases. Then several specific comparisons between subsets of the mutation types or locations were undertaken. We used $\chi^{2}$ tests for categorical variables and $t$ tests to compare means of continuous variables, using SAS/STAT ${ }^{\circledR}$ software. ${ }^{26}$ Centers for Disease Control growth charts ${ }^{27}$ were used for evaluating current height and weight measures.

\section{Mutation analysis}

DNA was extracted from blood samples collected in EDTA anticoagulant. Using a variety of template primers, ${ }^{18}$ the

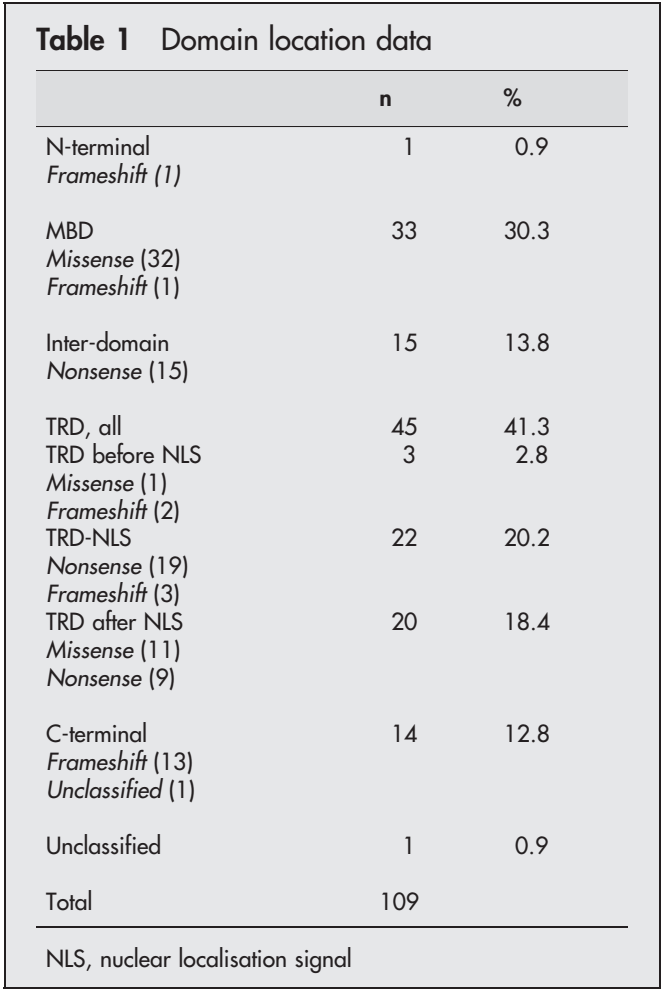

\section{$\mathrm{X}$ chromosome inactivation $(\mathrm{XCI})$}

$\mathrm{X}$ inactivation was quantified by examining the methylation status of each allele of the androgen receptor locus, after the method of Pegoraro et al. ${ }^{28}$ Microsatellites were analysed using Genescan (automated DNA analysis facility, University of NSW, Sydney, Australia). For scoring the X inactivation pattern we calculated the percentage of the smaller allele present. This was converted by a logistic transformation ${ }^{29}$ and values were compared using $t$ tests. ${ }^{26}$ 
Table 2 The most common mutations found in the cohort

\begin{tabular}{lrrl}
\hline Amino acid change & N & \multicolumn{1}{c}{$\%$} & Domain location \\
\hline R106W & 3 & 3.0 & MBD \\
R133C & 9 & 8.9 & MBD \\
T158M & 14 & 13.9 & MBD \\
R168X & 13 & 12.9 & Interdomain \\
R255X & 8 & 7.9 & TRD-NLS \\
R270X & 11 & 10.9 & TRD-NLS \\
R294X & 9 & 8.9 & TRD after NLS \\
R306C & 7 & 6.9 & TRD after NLS \\
Total & 74 & 73.3 & \\
Total number & & & \\
identified & 101 & & \\
\hline
\end{tabular}

MBD, methyl-CpG-binding domain; NLS, nuclear localisation signal; TRD, transcription repression domain.

\section{RESULTS}

\section{Mutation type}

When compared with those with all other mutation types, individuals with truncating mutations had an earlier onset of hand stereotypies: mean age 27 months $v 33$ months, $\mathrm{p}=0.04$. The Pineda score was higher (mean $17 v 15$, $\mathrm{p}=0.02$ ) and the WeeFIM score was lower (mean $27 v 31$, $\mathrm{p}=0.05$ ), implying a more severe phenotype. However, within the truncating mutation group, the frameshift cases were found to have a less severe phenotype, as indicated by later ages at onset of regression (mean age 42 months $v 30$ months, $p=0.04$ ) and loss of social interaction (mean age 24 months $v 19$ months, $\mathrm{p}=0.04$ ). On the other hand, cases with a nonsense mutation type had a more severe phenotype with age at losing social interaction significantly younger (mean age 17 months $v 22$ months, $\mathrm{p}=0.02$ ).

Mutations truncating in the NLS region were significantly more severe than other truncating mutations for several measures. The mean age at onset of epilepsy was younger (3.5 years $v 6.1$ years, $\mathrm{p}<0.001$ ) and the mean age at losing social interaction was also younger (15 months $v 22$ months, $\mathrm{p}=0.01$ ). Within the NLS group, $68 \%$ never walked, compared with $30 \%$ of the other truncating mutations $(p=0.04)$. All but the WeeFIM scale showed this group to have a more severe phenotype, with mean Kerr scores of $24 \mathrm{v}$ $22(\mathrm{p}=0.02)$, mean Percy scores of $28 v 24(\mathrm{p}=0.02)$, and
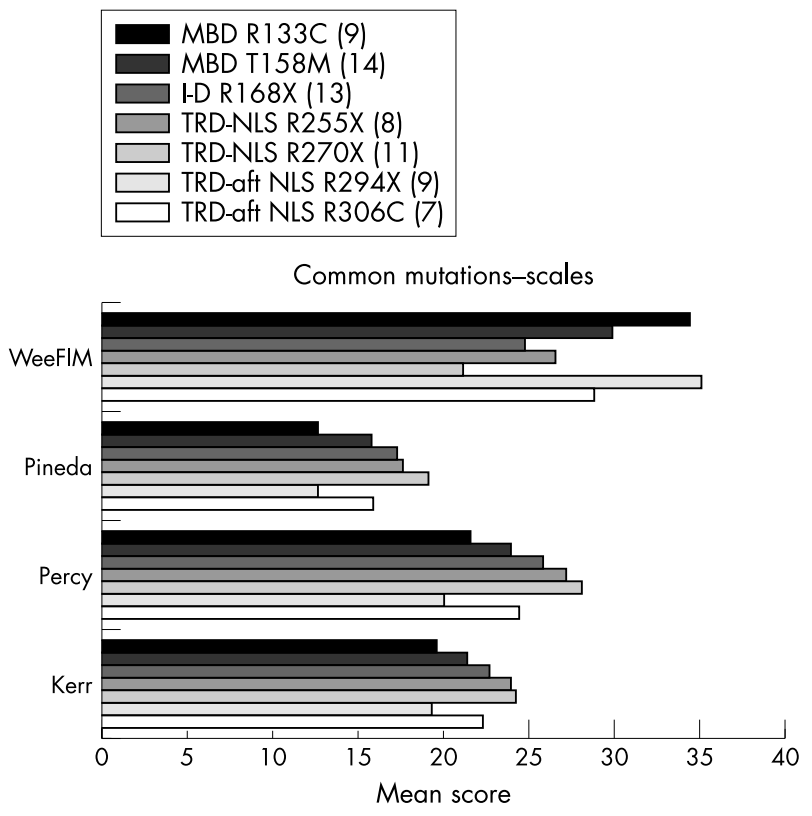

Figure 2 Common mutations. mean Pineda scores of $19 v 16(\mathrm{p}=0.01)$. Cases within this group were also more likely to be of shorter stature $(\mathrm{p}=0.04)$.

When truncating mutations in the C-terminal region were compared with all other truncating mutations, the phenotype was significantly less severe in two features: the mean age at losing social interaction was older (27 months $v 17$ months, $\mathrm{p}=0.002$ ) and the mean age at onset of regression was also later (50 months $v 29$ months, $\mathrm{p}=0.01$ ).

\section{Domain location}

Cases with mutations in the MBD region were found to have a less severe phenotype, with $22 \%$ having normal hand use compared with only $4 \%$ of the remainder $(p=0.01)$. This difference was also found when comparing the MBD region with the TRD region alone $(p=0.02)$. Similarly, $26 \%$ were currently walking normally compared with only $8 \%$ of those in other domains $(p=0.05)$.

Individuals with mutations in the TRD-NLS region had a more severe phenotype than those with mutations in other domains. Scores for all four scales were significantly more severe, with $\mathrm{p}$ values ranging from 0.002 for the Pineda score to 0.03 for the WeeFIM score. Ages at losing social interaction (mean age 15 months $v 21$ months, $\mathrm{p}=0.006$ ) and at onset of hand stereotypies (mean age 22 months $v 31$ months, $\mathrm{p}=0.04)$ were significantly earlier. Of those who developed epilepsy (similar proportions (77\%) in the TRD-NLS region and the remainder), age at onset was earlier in the TRD-NLS group (mean age 3.5 years $v 5.4$ years, $\mathrm{p}=0.05$ ). This group was less likely to have ever walked $(32 \% v 72 \%, \mathrm{p}=0.01)$, more likely to have never had hand use or to have completely lost hand use $(73 \% \vee 46 \%, p=0.06)$, and more likely to be of shorter stature $(76 \% \vee 51 \%$ under the third centile for age, $\mathrm{p}=0.05$ ).

Mutations in the TRD region after the NLS appeared to have a less severe influence on phenotype. Sixty per cent of these cases, compared with $44 \%$ of the remaining cases, retained some voluntary hand use $(p=0.05)$. The Pineda score also indicated a less severe phenotype (mean score $14 \mathrm{v}$ $16, \mathrm{p}=0.05)$.

Age at onset of regression was markedly later in the cases in the C-terminal region (mean age 50 months $v 30$ months, $\mathrm{p}=0.003)$. Similarly, age at losing social interaction was later (mean age 27 months $v 19$ months, $\mathrm{p}=0.004$ ).

\section{Common mutations}

Results for the R133C mutation have been reported previously $^{21}$ and showed a milder phenotype. Interestingly, for T158M-the other common mutation found in the MBD region-we did not find evidence of either a milder or a more severe phenotype when compared with the overall group.

Cases with the Rl68X mutation, which is located within the interdomain region, were more severe than the rest of the cohort in that the age at losing social interaction was earlier: $85 \% \vee 55 \%$ were less than 18 months of age $(\mathrm{p}=0.04)$ at the time. For the R255X mutation, located within the TRD-NLS region, no significant differences in phenotype severity were identified in comparison with the rest of the cohort. However, the phenotype associated with the R270X mutation, also in the TRD-NLS region, was clearly more severe than the rest of the cohort as a group. The mean Pineda score was higher $(19 v 16, \mathrm{p}=0.01)$ and the mean WeeFIM score lower $(21 v$ $29, \mathrm{p}=0.04)$, age at losing social interaction was younger (mean age 14 months $v 20$ months, $\mathrm{p}=0.05$ ), and so was the age at onset of hand stereotypies, at 19 months $v 30$ months, $\mathrm{p}=0.04$ (table 3). When we compared the R255X and R270X mutations directly we did not find any results of significance to distinguish them. 
On the other hand, the other nonsense mutation, R294X, located after the TRD-NLS region, had a milder phenotype than the rest of the cohort as a group, with lower Pineda (mean $13 v 16, \mathrm{p}=0.02$ ) and Percy scores (mean $20 v 25$, $\mathrm{p}=0.03)$. More cases had some voluntary hand use $(78 \% v$ $44 \%, p=0.03)$ and all cases had walked, compared with only $60 \%$ in the remainder of cases $(p=0.05)$. The R306C mutation was also milder in that the onset of regression for all cases was after 18 months, compared with only $80 \%$ in the remainder of the cases $(p=0.05)$.

We also directly compared two nonsense mutations that are close to each other but in different parts of the same domain region. R270X is in the TRD-NLS region and R294X is after the NLS but still in the TRD region. R270X was significantly more severe than R294X in many features. All four scales indicated a more severe phenotype: mean Kerr score, $24 v 19 \quad(\mathrm{p}=0.006)$; mean Percy score, $28 v 20$ $(\mathrm{p}=0.007)$; mean Pineda score, $19 v 13(\mathrm{p}<0.0001)$; and mean WeeFIM score, $21 v 35(\mathrm{p}=0.001)$. The mean age at losing social interaction was younger, at 14 months $v 23$ months $(p=0.04)$, ambulation was severely affected, with $73 \%$ v $0 \%$ never walking $(\mathrm{p}=0.009)$; voluntary hand use was more severe, with 73\% v 22\% having none; and the latest weight $z$ score was significantly lower $(-4.6 v-1.4$, $\mathrm{p}=0.01)$. Table 3 highlights the difference between the mean scores for each of the common mutations and in particular the large difference between these two mutations.

\section{$\mathrm{X}$ chromosome inactivation status $(\mathrm{XCI})$}

XCI testing was completed on 94 of the 109 cases. After excluding the 10 who were homozygous, 37\% (31/84) were shown to have skewed XCI. We did not find any significant relations between domain location or mutation type and XCI, using a logistic transformation of the percentage of the smaller allele present. The only XCI results of any note were associated with two individual mutations. Compared with cases with other mutations, there was more skewing associated with the more severe mutation, R255X $(p=0.02)$, and less with the milder mutation, R306C $(p=0.06)$. There were also no significant relations found between any of the phenotype features and XCI.

Of interest was the proportion of R133C cases with skewed $\mathrm{XCI}$ (where skewing was defined as greater than $75 \%$ of one $X$ allele present)—only two of eight cases. Similarly, R306C had only one of six with skewed XCI and it also appears to have a milder phenotype. The proportions of XCI are given in table 4 .

\section{DISCUSSION}

While the outcomes of previous research attempting to identify relations between phenotypic characteristics and mutation type have been inconsistent, our findings do support those of Cheadle et al, ${ }^{18}$ Monros et al, ${ }^{15}$ Huppke et $a l^{30}$ and one of our previous studies, ${ }^{22}$ where a milder phenotype was found in individuals with missense mutations.

We followed a similar system to Huppke et al ${ }^{30}$ with respect to domain, in that we considered the TRD-NLS as a separate category from the rest of the TRD. Overall we found that mutations in this location were significantly more severe in terms of all four composite scores as well as in certain key variables such as age at onset of hand stereotypies and age at loss of social interaction. Huppke et al also found that this group had significantly higher severity scores than those with both MBD and other TRD mutations. Hoffbuhr et al did not single out this subset of severe mutations as they assigned all TRD nonsense mutations to one group. ${ }^{31}$ As in the results reported by Huppke et al,,$^{30}$ the only significant difference between TRD and MBD mutations was in voluntary hand use. Our findings of a less severe phenotype in the region after the TRD-NLS including the C-terminal region would also be in keeping with their results. In a study focusing on preserved speech, Zappella et al suggested that, along with missense mutations, late truncating mutations were a group more likely to be associated with this milder variant. ${ }^{32}$

Truncating mutations involving the NLS might be predicted to result in failure of the shortened MeCP2 protein (if structurally stable) to be directed to the nucleus, resulting in a more significant reduction in MeCP2 specific transcription repression, and could conceivably lead to a more severe clinical phenotype. Truncation mutations involving the TRD, but distal to the NLS, might still be targeted to the nucleus and be able to exert a partial effect on transcription repression through other pathways-for instance, pathways involving c-Ski and $\mathrm{N}$-COR. ${ }^{33}$ To our knowledge, in vitro functional studies of mutations involving the NLS have not been done up to now, and this would be of considerable interest.

In a previous report in which we described the mild phenotype of the R133C mutation, ${ }^{21}$ we emphasised the need now to progress beyond the examination of mutation groupings and to start studying individual mutations, especially those that are common. Considering that currently these common mutations account for about $70 \%$ of the pathogenic mutations being identified in patients, refining

Table 3 Common mutations and mean values

\begin{tabular}{|c|c|c|c|c|c|c|c|}
\hline & \multicolumn{2}{|l|}{ MBD } & \multirow{2}{*}{$\begin{array}{l}\begin{array}{l}\text { Inter- } \\
\text { domain }\end{array} \\
\mathrm{R} 168 \mathrm{X}\end{array}$} & \multicolumn{2}{|c|}{ TRD-NLS } & \multicolumn{2}{|c|}{ TRD after NLS } \\
\hline & $\mathrm{R} 133 \mathrm{C}$ & $\mathrm{T} 158 \mathrm{M}$ & & R255X & R270X & R294X & R306C \\
\hline $\begin{array}{l}\text { Age at losing social interaction } \\
\text { (months) }\end{array}$ & 23.5 & 16.3 & 15.7 & 15.4 & 14.5 & 22.8 & 20.5 \\
\hline $\begin{array}{l}\text { Age at onset of regression } \\
\text { (months) }\end{array}$ & 35.0 & 27.4 & 25.1 & 20.9 & 28.5 & 45.1 & 22.8 \\
\hline $\begin{array}{l}\text { Age at onset of hand } \\
\text { stereotypies (months) }\end{array}$ & 40.3 & 27.5 & 22.3 & 24.0 & 19.0 & 36.0 & 33.0 \\
\hline Age at sitting alone (months) & 7.5 & 7.8 & 7.9 & 7.8 & 7.1 & 7.2 & 7.3 \\
\hline Age at onset of epilepsy (years) & 7.3 & 4.4 & 5.7 & 2.3 & 4.1 & 5.9 & 5.5 \\
\hline Latest weight $z$ score & -2.7 & -1.8 & -3.4 & -2.6 & -4.6 & -1.4 & -3.2 \\
\hline Latest height $z$ score & -2.6 & -1.6 & -2.6 & -2.1 & -2.7 & -1.5 & -2.3 \\
\hline Kerr scale & 19.5 & 21.3 & 22.6 & 23.9 & 24.2 & 19.3 & 22.3 \\
\hline Percy scale & 21.5 & 23.9 & 25.8 & 27.0 & 28.0 & 20.0 & 24.4 \\
\hline Pineda scale & 12.7 & 15.7 & 17.2 & 17.6 & 19.1 & 12.6 & 15.8 \\
\hline WeeFIM scale & 34.3 & 29.8 & 24.7 & 26.5 & 21.0 & 34.9 & 28.7 \\
\hline
\end{tabular}


Table $4 \mathrm{X}$ chromosome inactivation and the common mutations

\begin{tabular}{lcccll}
\hline Amino acid change & $\mathbf{n}$ & XCl tested & Skewed $(\mathbf{n})$ & Skewed (\%) & Domain location \\
\hline R133C & 9 & 8 & 2 & 25 & MBD \\
T158M & 14 & 11 & 5 & 45 & MBD \\
R168X & 13 & 10 & 2 & 20 & Interdomain \\
R255X & 8 & 5 & 3 & 60 & TRD-NLS \\
R270X & 11 & 9 & 1 & 11 & TRD-NLS \\
R294X & 9 & 8 & 4 & 50 & TRD after NLS \\
R306C & 7 & 6 & 1 & 17 & TRD after NLS \\
Totals & 71 & 57 & 18 & 32 & \\
All other mutations & 30 & 27 & 13 & 48 & \\
Total number identified & 101 & 84 & 31 & 37 & \\
\multicolumn{7}{l}{ NLS, nuclear localisation signal; XCl, X chromosome inactivation. } \\
\hline
\end{tabular}

their phenotype should have the greatest clinical relevance and benefit. In this respect the most outstanding findings from this study relate to two of these common mutations.

We have shown that R270X has the most severe score for each of the four composite scales, being significantly higher for the Pineda scale and lower in the WeeFIM scale. In terms of individual items, both age at onset of hand stereotypies and loss of social interaction were earlier. On the other hand, another of the four common nonsense mutations-R294X, situated in the TRD after the NLS-has scores overall that are comparable in mildness to R133C, with milder Pineda and Percy scores. Ambulatory and hand function scores were also significantly better. In early classification systems, both the R270X and the R294X would have been grouped together as TRD nonsense mutations and would not have been treated as individual entities. The epidemiological infrastructure now in place in Australia and developed over the last decade to provide phenotypic and now molecular data has given us the capacity to separate out the clinical characteristics of these two mutations. We now know that children with the R270X are likely to lose skills such as motor function, hand use, and social interaction earlier, and to function overall more poorly, than their counterparts with the R294X. The latter, on the other hand, are likely to be mobile and less likely to have growth or nutritional problems. This sort of information is extremely relevant for clinicians and families at the time of diagnosis.

Like others, we have at this point used severity scores that are weighted towards the biological severity of the disease. As pointed out by Huppke et al, ${ }^{30}$ this may not reflect the social severity. Thus girls with a milder phenotype, being more mobile, may well have more challenging behaviours. Further research is needed to specifically compare behavioural phenotype with genetic characteristics. This will be possible using items from the behavioural checklist available from the work of Mount et al..$^{34}$

In contrast to the R270X and R294X mutations, there was no feature of the phenotype associated with T158M, the most common mutation, which stood out as being statistically different from the rest of the mutations. It is our clinical experience that there is considerable variability within this mutation but from the present study we have not been able to identify potential drivers of this variability.

In this study we did not find any significant effect of skewing of $\mathrm{X}$ inactivation on phenotype. Such effects have been reported in association with individual cases of classical and atypical Rett syndrome $e^{143135}$ and with mild learning disability caused by a MECP2 mutation. ${ }^{36}$ Skewed X inactivation has also been found in apparently normal carrier mothers. ${ }^{14}{ }^{31}{ }^{37-39}$ However, until now only Nielsen et al ${ }^{40}$ and Hoffbuhr $e t a^{31}$ have attempted to investigate the relation between $\mathrm{X}$ inactivation ratios and a clinical severity score in a series of cases. Nielsen et al evaluated cases using a score based on hand function, eye contact, and gait function, but did not have sufficient cases for statistical evaluation $(\mathrm{n}=30) \cdot{ }^{40}$ They could not relate the XCI pattern to phenotype. We had previously found no evidence to suggest that the milder of the R133C cases were likely to have skewing of $X$ inactivation but rather the reverse. ${ }^{21}$ These results are somewhat at variance with those of Hoffbuhr et al, ${ }^{31}$ who found a relation between skewing of $X$ inactivation and clinical severity in mutations closer to the $\mathrm{N}$ terminal but not with more distal mutations. If phase can be determined in future studies-that is, whether the normal or mutated gene is being preferentially inactivated-the effects or otherwise of $\mathrm{X}$ inactivation on phenotype will probably become much clearer.

We have continued to use composite scales and their individual components developed by others and including both the diagnostic criteria and other clinical features of Rett syndrome. Previously ${ }^{11}$ we showed that the Pineda scale appeared to be most independent of age because it was based more on developmental than current data. Again in this study we found that the Pineda scale appears to be the most discriminating in that it was the one that more often identified phenotypic differences. Similarly we also found that there were some individual items that are likely to be better predictors than others of these differences. Particular examples are age at onset of hand stereotypies, age of losing social interaction, and voluntary hand use. The items that we found to be particularly helpful tended to be different from those identified by Huppke et al. In our studies we considered a recent proposal by Huppke and colleagues ${ }^{41}$ for a checklist to be used as a guide for genetic screening, but were unable to use their classification system as it was strongly dependent on having available information and clinical characteristics at the age of five years. Such information was not consistently available to us. We also had concerns about whether it is appropriate at this stage to weight language and hand skills more than the other diagnostic criteria. It would have been interesting to see if the same effect could be determined by weighting all other items in their checklist as a score of 0 or 2 and the hand skills and speech as 0,1 , or 2 .

Further work is still needed to improve these items and scales in preparation for the more complex analyses that will be needed in the future. From a clinical perspective it is important to establish the relation between early symptoms and later outcomes so that, in conjunction with molecular data, the child's prognosis and the likely future needs of the family can be predicted.

The development of international infrastructure and collaborative arrangements, ${ }^{25}{ }^{42}$ enhanced by the use of web based technology, will provide much larger samples of better characterised cases. These mechanisms will allow us to examine the phenotype of some of the more rare mutations in the same way as the ARSD is helping us describe these common mutations. They will also provide more power to examine the complex interactions that may be occurring 
between specific mutations, $\mathrm{X}$ inactivation status, and other epigenetic factors.

\section{ACKNOWLEDGEMENTS}

We would like to thank the clinicians who have reported cases and the families for their ongoing participation in our study, and in particular Bill Callaghan and the Lillis and Aitken families. We would also like to acknowledge the Australian Paediatric Surveillance Unit and the Rett Syndrome Association of Australia for their support. Funding for this project has been provided by the Financial Markets Foundation for Children, the International Rett Syndrome Association, and the Rett Syndrome Australian Research Fund. HL is part funded by NHMRC programme grant 003209. The Sydney research group was also in part funded by NHMRC project grant 185202. We would also like to acknowledge Bruce Bennetts and Catherine Stevenson for their contributions to the molecula laboratory work and Dr Carolyn Ellaway for her contribution to the clinical data.

\section{Authors' affiliations}

L Colvin, H Leonard, N de Klerk, Centre for Child Health Research, The University of Western Australia, Telethon Institute for Child Health Research, Perth, Western Australia, Australia

M Davis, Centre for Neuromuscular and Neurological Disorders, University of Western Australia

L Weaving, J Christodoulou, Discipline of Paediatrics and Child Health, University of Sydney, New South Wales, Australia

L Weaving, S Williamson, J Christodoulou, Western Sydney Genetics Program, Children's Hospital at Westmead, New South Wales

Correspondence to: Dr Helen Leonard, Telethon Institute for Child Health Research, PO Box 855, West Perth WA 6872, Australia; hleonard@ichr.uwa.edu.au

Received 5 June 2003

Accepted 18 August 2003

\section{REFERENCES}

1 Leonard H, Bower C, English D. The prevalence and incidence of Rett syndrome in Australia. Eur Child Adolesc Psychiatry 1997;6(suppl 1):8-10.

2 Budden S. Rett syndrome: studies of 13 affected girls. Am J Med Genet 1986;24:99-109.

3 Coleman M, Brubaker J, Hunter K, Smith G. Rett syndrome: a survey of North American patients. J Ment Defic Res 1988;32:117-24.

4 Kerr A, Stephenson JBP. A study of the natural history of Rett syndrome in 23 girls. Am J Med Genet 1986;24(suppl 1):77-83.

5 Naidu S, Murphy M, Moser H, Rett A. Rett syndrome - natural history in 70 cases. Am J Med Genet 1986;24(suppl 1):61-72.

6 Hagberg B, Aicardi J, Dias K, Ramos O. A progressive syndrome of autism, dementia, ataxia, and loss of purposeful hand use in girls: Rett's syndrome: report of 35 cases. Ann Neurol 1983;14:471-9.

7 Trevathan E, Naidu S. The clinical recognition and differential diagnosis of Rett syndrome. J Child Neurol 1988:3(suppl):S6-16.

8 Amir RE, Van den Veyver IB, Wan M, Tran CQ, Francke U, Zoghbi HY. Rett syndrome is caused by mutations in X-linked MECP2, encoding methyl-CpG binding protein 2. Nat Genet 1999;23:185-8.

9 Hagberg BA, Skjeldal $\mathrm{OH}$. Rett variants: a suggested model for inclusion criteria. Pediatr Neurol 1994;11:5-11.

10 Hagberg B, Hanefeld F, Percy A, Skjeldal O. An update on clinically applicable diagnostic criteria in Rett syndrome. Comments to Rett Syndrome Clinical Criteria Consensus Panel Satellite to European Paediatric Neurology Society Meeting, Baden Baden, Germany, 11 September 2001. Eur J Paediatr Neurol 2002;6:293-7.

11 Colvin L, Fyfe S, Leonard S, Schiavello T, Ellaway C, de Klerk N Christodoulou J, Msall M, Leonard H. Describing the phenotype in Rett syndrome using a population database. Arch Dis Child 2003;88:38-43.

12 Msall ME, DiGaudio K, Rogers BT, LaForest S, Catanzaro NL, Campbell J, Wilczenski F, Duffy LC. The Functional Independence Measure for Children (WeeFIM). Conceptual basis and pilot use in children with developmental disabilities. Clin Pediatr (Phila) 1994;33:421-30.

13 Kerr AM, Nomura Y, Armstrong D, Anvret M, Belichenko PV, Budden S, Cass H, Christodoulou J, Clarke A, Ellaway C, d'Esposito M, Francke U, Hulten M, Julu P, Leonard H, Naidu S, Schanen C, Webb T, Witt Engerstrom I, Yamashita Y, Segawa M. Guidelines for reporting clinical features in cases with MECP2 mutations. Brain Dev $2001 ; 23: 208-11$

14 Amir RE, Van den Veyver IB, Schultz R, Malicki DM, Tran CQ, Dahle EJ, Philippi A, Timar L, Percy AK, Motil KJ, Lichtarge O, Smith EO, Glaze DG Zoghbi HY. Influence of mutation type and X chromosome inactivation on Rett syndrome phenotypes. Ann Neurol 2000;47:670-9.
15 Monros E, Armstrong J, Aibar E, Poo P, Canos I, Pineda M. Rett syndrome in Spain: mutation analysis and clinical correlations. Brain Dev $2001 ; 23$ (suppl 1):S251-3

16 Amano K, Nomura Y, Segawa M, Yamakawa K. Mutational analysis of the MECP2 gene in Japanese patients with Rett syndrome. J Hum Genet 2000:45:231-6.

17 Amir RE, Zoghbi HY. Rett syndrome: methyl-CpG-binding protein 2 mutations and phenotype-genotype correlations. Am J Med Genet 2000;97:147-52.

18 Cheadle JP, Gill H, Fleming N, Maynard J, Kerr A, Leonard H, Krawczak M, Cooper DN, Lynch S, Thomas N, Hughes H, Hulten M, Ravine D, Sampson JR, Clarke A. Long-read sequence analysis of the MECP2 gene in Rett syndrome patients: correlation of disease severity with mutation type and location. Hum Mol Genet 2000;9:1 119-29.

19 Huppke P, Laccone F, Kramer N, Engel W, Hanefeld F. Rett syndrome: analysis of MECP2 and clinical characterization of 31 patients. Hum Mol Genet 2000;9:1369-75

20 Invi K, Akagi M, Ono J, Tsukamoto H, Shimono K, Mano T, Imai K, Yamada M, Muramatsu T, Sakai N, Okada S. Mutational analysis of MECP2 in Japanese patients with atypical Rett syndrome. Brain Dev $2001 ; 23: 212-15$.

21 Leonard H, Colvin L, Christodoulou J, Schiavello T, Weaving L, Williamson S, MD, Ravine D, Fyfe S, de Klerk N, Matsuishi T, Kondo I, Clarke A, Hackwell S, Yamashita Y. Patients with the R133C mutation: is their phenotype different from Rett syndrome patients with other mutations? J Med Genet 2003:40:e53.

22 Weaving LS, Williamson SL, Bennetts B, Davis M, Ellaway CJ, Leonard H, Keong Thong MK, Delatycki M, Thompson EM, Laing N, Christodoulou J. Effects of MECP2 mutation type, location and X-inactivation in modulating Reft syndrome phenotype. Am J Med Genet 2003;118A:103-14.

23 Van den Veyver IB. Skewed X inactivation in X-linked disorders. Semin Reprod Med 2001;19:183-91.

24 Dragich J, Houwink-Manville I, Schanen C. Rett syndrome: a surprising result of mutation in MECP2. Hum Mol Genet 2000;9:2365-75.

25 Christodoulou J, Grimm A, Maher T, Bennetts B. RettBASE: the IRSA MECP2 variation database - a new mutation database in evolution. Hum Mutat 2003;21:466-72

26 SAS/STAT. The data analysis for this paper was generated using SAS/STAT software, release 8.01 of the SAS System for Windows. Copyright (C)19992000. Cary, NC: SAS Institute, 2000.

27 Ogden C, Kuczmarski R, Flegal K, Mei Z, Guo S, Wei R, Grummer-Strawn L, Curtin L, Roche A, Johnson C. Centers for Disease control and Prevention 2000, growth charts for the United States: improvements to the 1977 National Center for Health Statistics version. Pediatrics 2002;109:45-60.

28 Pegoraro E, Schimke RN, Arahata K, Hayashi Y, Stern H, Marks H, Glasberg MR, Carroll JE, Taber JW, Wessel HB, et al. Detection of new paternal dystrophin gene mutations in isolated cases of dystrophinopathy in emales. Am J Hum Genet 1994:54:989-1003.

29 Armitage P. Statistical methods in medical research. Oxford: Blackwell Scientific Publications, 1971

30 Huppke $\mathbf{P}$, Held M, Hanefeld F, Engel W, Laccone F. Influence of mutation type and location on phenotype in 123 patients with Rett syndrome. Neuropediatrics 2002;33:63-8.

31 Hoffbuhr K, Devaney JM, LaFleur B, Sirianni N, Scacheri C, Giron J, Schuette J, Innis J, Marino M, Philippart M, Narayanan V, Umansky R, Kronn D, Hoffman EP, Naidu S. MeCP2 mutations in children with and without the phenotype of Rett syndrome. Neurology 2001;56:1486-95.

32 Zappella M, Meloni I, Longo I, Hayek G, Renieri A. Preserved speech variants of the Rett syndrome: molecular and clinical analysis. Am J Med Genet 2001;104:14-22

33 Kokura K, Kaul SC, Wadhwa R, Nomura T, Khan MM, Shinagawa T, Yasukawa T Colmenares $\mathrm{C}$, Ishii S. The Ski protein family is required for MeCP2-mediated transcriptional repression. J Biol Chem 2001;276:34115-21.

34 Mount RH, Charman T, Hastings RP, Reilly S, Cass H. The Rett Syndrome Behaviour Questionnaire (RSBQ): refining the behavioural phenotype of Rett syndrome. J Child Psychol Psychiatry 2002;43:1099-110.

35 Nielsen JB, Ravn K, Schwartz M. A 77-year-old woman and a preserved speech variant among the Danish Rett patients with mutations in MECP2. Brain Dev 2001;23(suppl 1):S230-2

36 Wan M, Lee SS, Zhang X, Houwink-Manville I, Song HR, Amir RE, Budden S, Naidu S, Pereira JL, Lo IF, Zoghbi HY, Schanen NC, Francke U. Rett syndrome and beyond: recurrent spontaneous and familial MECP2 mutations at $\mathrm{CpG}$ hotspots. Am J Hum Genet 1999:65:1520-9.

37 Bienvenu T, Carrie A, de Roux N, Vinet MC, Jonveaux P, Couvert P, Villard L, Arzimanoglou A, Beldjord C, Fontes M, Tardieu M, Chelly J. MECP2 mutations account for most cases of typical forms of Rett syndrome. Hum Mol Genet 2000:9:1377-84.

38 Sirianni N, Naidu S, Pereira J, Fernando R, Hoffman EP. Rett-syndrome confirmation of $X$-linked dominant inheritance, and localization of the gene to Xq28. Am J Hum Genet 1998;63:1552-8.

39 Villard L, Cardoso AK, Chelly PJ, Tardieu PM, Fontes M. Two affected boys in a Rett syndrome family: clinical and molecular findings. Neurology 2000;55:1188-93.

40 Nielsen JB, Henriksen KF, Hansen C, Silahtaroglu A, Schwartz M, Tommerup N. MECP2 mutations in Danish patients with Rett syndrome: high frequency of mutations but no consistent correlations with clinical severity or with the $X$ chromosome inactivation pattern. Eur J Hum Genet 2001;9:178-84.

41 Huppke P, Köhler K, Laccone F, Hanefeld F. Indication for genetic testing: a checklist for Rett syndrome. J Pediatr 2003;142:332-5.

42 Fyfe S, de Klerk N, Cream A, Christodoulou J, Leonard H. MECP2 and InterRett: International IRSA databases for Rett syndrome. J Child Neurol 2003; 18:709-13. 